\title{
Infiltrative angiolipoma of the parotid salivary gland in a dog
}

\author{
A M Kitshoff ${ }^{\mathrm{a}^{*}}$, I R Millward ${ }^{\mathrm{a}}$, J H Williams ${ }^{\mathrm{b}}$, S J Clift ${ }^{\mathrm{b}}$ and R M Kirberger ${ }^{\mathrm{c}}$
}

\begin{abstract}
Solitary benign angiolipoma and infiltrative angiolipoma are rare tumours in dogs. Angiolipomata can be distinguished histologically from lipomata by the large number of tightly packed blood vessels seen between the adipocytes with multiple fibrin thrombi occupying some of the vessels' lumens. The dog presented with a solitary slow-growing mass in the cervical region. Histopathology revealed multifocal to coalescing single or clusters of blood-filled vessels lined by flattened endothelial cells with narrow, elongated, basophilic nuclei. These regions were embedded in adipose tissue with multifocal areas of intervascular remnants of differentiated serous salivary glandular tissue with multifocal small ducts. Fibrin thrombi occupied a few of the vessel lumens. A histological diagnosis of infiltrative angiolipoma was made. On computed tomography, the mass was bilobed with a suspected primary component involving the right parotid gland which was grossly enlarged. The mass had a slightly hypoattenuating mottled to lobulated appearance with a few hyperattenuating mineralised specks throughout. Hounsfield units of the mass ranged between 40 and 45 , which was less than the 60-65 of the contralateral salivary glands and cranial musculature. Post contrast images showed no contrast enhancement of $90 \%$ of the mass with only a band of peripheral contrast uptake of the affected lateral lobe.
\end{abstract}

Keywords: angiolipoma, computed tomography, dog, histopathology, infiltrative, parotid, salivary gland.

Kitshoff A M, Millward I R, Williams J H, Clift S J, Kirberger R M Infiltrative angiolipoma of the parotid salivary gland in a dog. Journal of the South African Veterinary Association 81(4): 258-261 (En.). Section of Small Animal Surgery, Department of Companion Animal Clinical Studies, Faculty of Veterinary Science, University of Pretoria, Private Bag X04, Onderstepoort, 0110 South Africa.

\section{INTRODUCTION}

According to the World Health Organisation (WHO) classification of mesenchymal soft tissue tumours in domestic animals, benign tumours originating from adipose tissue can be divided into lipomata (with a sub classification of infiltrative lipomata) and angiolipomata ${ }^{7}$. In contrast to domestic animals, 14 types of benign tumours of adipose tissue are recognised in humans ${ }^{4}$. Lipomata consist of large adipocytes that are tightly packed and contain eccentric, dense nuclei and account for $7.1 \%$ of all cutaneous tumours of non-lymphoid origin and occur in $16 \%$ of all dogs 5,22 .

aSection of Small Animal Surgery, Department of Companion Animal Clinical Studies, Faculty of Veterinary Science, University of Pretoria, Private Bag X04, Onderstepoort, 0110 South Africa.

${ }^{b}$ Section of Pathology, Department of Paraclinical Sciences, Faculty of Veterinary Science, University of Pretoria, Private Bag X04, Onderstepoort, 0110 South Africa.

'Section of Diagnostic Imaging, Department of Companion Animal Clinical Studies, Faculty of Veterinary Science, University of Pretoria, Private Bag X04, Onderstepoort, 0110 South Africa.

*Author for correspondence.

E-mail: adriaan.kitshoff@up.ac.za

Received: June 2010. Accepted: October 2010.
Angiolipomata reported in dogs include 2 variants and are classified as infiltrative or non-infiltrative, as is done for lipomata $^{10,19}$. Angiolipomata, infiltrating angiolipomata and infiltrating lipomata are far less common than lipomata in veterinary medicine and canine infiltrating angiolipomata have only been reported twice previously ${ }^{8,10}$. The solitary benign angiolipomata are commonly found in the subcutaneous tissue of the trunk $^{1,10}$. This report documents a case of infiltrating angiolipoma of the parotid salivary gland in a dog.

\section{CASE HISTORY}

A 6-year-old, $43.5 \mathrm{~kg}$, spayed Boerboel bitch presented with a palpably firm, well circumscribed oval mass, attached to the underlying structures, on the right side of the neck, just caudal to the angle of the mandible and ventral to the ear. The mass measured $10 \times 5 \times 5 \mathrm{~cm}$ and was reported to have been growing slowly over approximately 18 months. Clinical examination revealed a healthy dog with no detectable abnormalities. Fine-needle aspirates were taken from the mass and yielded blood-diluted samples with inconclusive cytological findings. Ultrasound examination of the cervical mass was done using a Sonoline Omnia ultrasound machine (Siemens AG, Erlangen, Germany) with a multifrequency curvilinear array transducer operated at 7.5 MHz. The mass appeared well marginated, bilobed and hyperechoic with a slightly mottled echotexture. The caudolateral lobe measured $60 \times 17 \mathrm{~mm}$ and the craniomedial lobe $46 \times 17 \mathrm{~mm}$. The latter was located just caudal to the horizontal ear canal. A provisional ultrasonographic diagnosis of salivary gland infection and reactive lymphadenopathy was made.

No abnormalities were detected on thoracic radiographs taken for evaluation of lung metastases. This did not, however, rule out metatstatic nodules, which are more readily detected by computed tomography $(\mathrm{CT})^{16}$.

An incisional biopsy was taken from the mass. No infiltration of the mass was seen macroscopically in the skin and subcutaneous tissues. The mass was covered by a thin fibrous pseudocapsule on which multiple small $(1 \times 2 \times 1 \mathrm{~mm})$ islands of raised purplish tissue could be seen which were presumed to be tumour infiltration. The pseudocapsule was incised and a wedge biopsy taken, after which the capsule was sutured and the incision closed routinely. A minor amount of bleeding was present. A $3 \times 4 \times 2 \mathrm{~cm}$ haematoma developed ventral to the incision line following surgery, which resolved. The gross pathological appearance of the $1.5 \times 1 \times 0.5 \mathrm{~cm}$ formalin-fixed biopsy was mottled with small yellowish-white slightly raised areas (Fig. 1). Examination of haematoxylin \& eosinstained, routinely prepared sections by light microscopy revealed multifocal to coalescing single or clusters of blood-filled vessels lined by flattened endothelial cells with narrow, elongated, basophilic nuclei; however, occasional nuclei were slightly plump. These regions were surrounded by and embedded in adipose tissue and there was a thin intervascular fibrous connective tissue stroma. Within this region there were multifocal regions of intervascular remnants of differentiated 
serous salivary glandular tissue with multifocal small ducts (Fig. 2). Fibrin thrombi occupied a few of the vessel lumens (Fig. 3).

Blood oozed from the incision line starting 4 days after the biopsies were taken. The aetiology was uncertain but trauma to the area was suspected. Two weeks later the dog had a CT examination to evaluate potential thoracic metastasis and the extent of the mass and infiltration for surgical planning. At presentation the dog had a small $1 \times 2 \mathrm{~cm}$ well granulating wound in the distal aspect of the original biopsy site. The dog was premedicated intravenously with morphine sulphate (Morphine sulphate Fresenius PF, Fresenius $\mathrm{kabi}, 10 \mathrm{mg} / \mathrm{m}$ ) at a dose of $0.2 \mathrm{mg} / \mathrm{kg}$ and diazepam (Pax, Aspen pharmacare, $10 \mathrm{mg} / 2 \mathrm{ml}$ ) at a dose of $0.4 \mathrm{mg} / \mathrm{kg}$. Five minutes later the dog was induced with intravenous Propofol (Diprivan, AstraZeneca, $10 \mathrm{mg} / \mathrm{ml}$ ) at a dose of $4 \mathrm{mg} / \mathrm{kg}$ and maintained under anaesthesia using isoflurane (Halocarbon, Halocarbon Products Corporation). The patient was placed symmetrically in sternal recumbency with her thoracic limbs pulled cranially. A CT was performed with an Emotion Duo helical dual slice CT machine (Siemens AG, Erlangen, Germany). Non-contrast scans were performed on the thorax and head region followed by manual intravenous contrast administration $(1 \mathrm{ml} / \mathrm{kg}$ Iohexal 300 $\mathrm{mgI} / \mathrm{m} \ell$ (Omnipaque 300, GE Healthcare)) as a bolus followed 5 minutes later by another head scan. The images were examined in bone, lung and soft tissue windows and were reconstructed into dorsal and sagittal planes. There was no evidence of thoracic or regional lymph node metastasis or underlying osseous changes. The mass was bilobed with a suspected primary component involving the right parotid gland which was grossly enlarged and measured $81 \times 27 \times 29 \mathrm{~mm}$. Cranioventrally the mass extended medially to form another lobe measuring $56 \times$ $31 \times 49 \mathrm{~mm}$ medial to the mandibular salivary gland. The mass displaced the trachea and associated structures to the left and ipsilateral mandibular salivary gland to the right. The mass had a slightly hypo-attenuating mottled to lobulated appearance with a few hyperattenuating mineralised specks throughout. Ventrolaterally to the mass 2 small pockets of gas were seen. The mass appeared to involve the insertions of both the sternothyroideus and the sternohyoideus muscles. The Hounsfield units (HU) of the mass were in the range of $40-45$, which was less than the 60-65 of the contralateral salivary glands and cranial musculature. Post contrast images of the mass

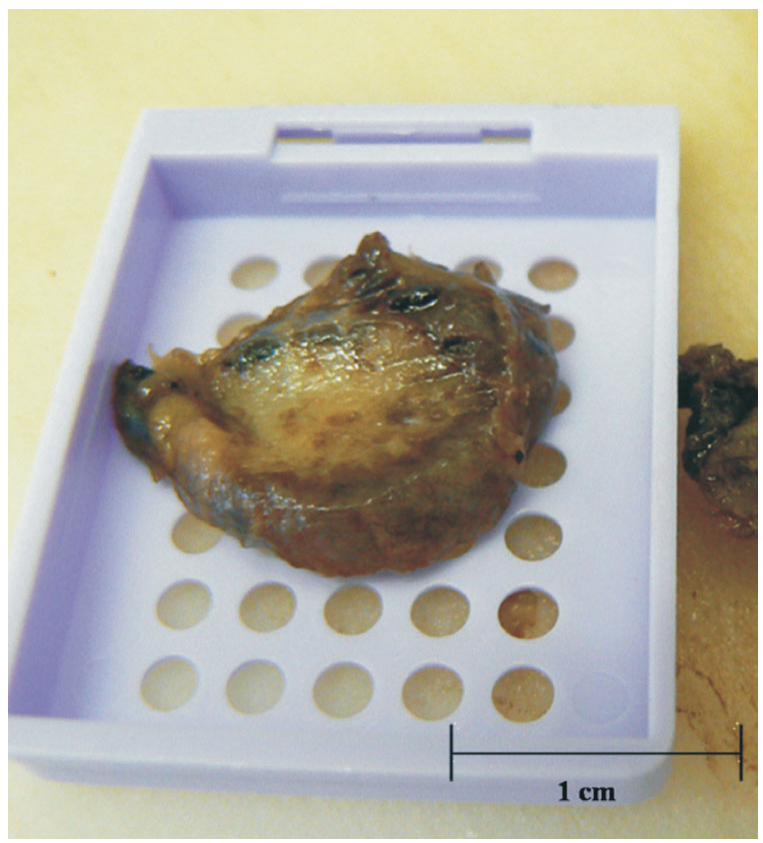

Fig. 1: Cut surface of the formalin-fixed biopsy showing the gross pathology. Note the mottled appearance with slightly raised, small, yellowish-white areas.

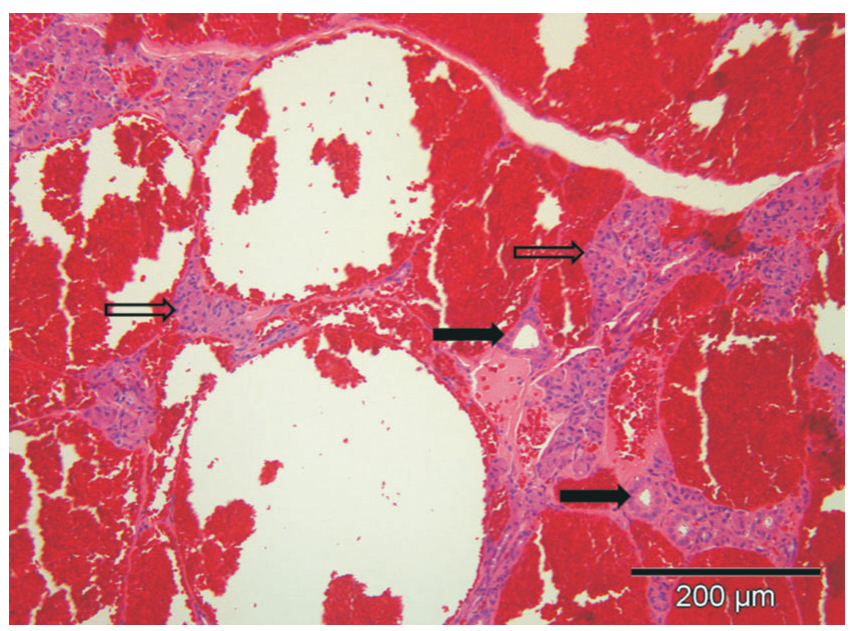

Fig. 2: Haematoxylin \& eosin-stained routinely prepared histopathology sections showing multifocal to coalescing single or clusters of blood-filled vessels lined by flattened endothelial cells with narrow, elongated, basophilic nuclei. These regions were surrounded by and embedded in adipose tissue. Intervascular multifocal regions of serous salivary glandular tissue (open arrows) with multifocal small salivary ducts (solid arrow).

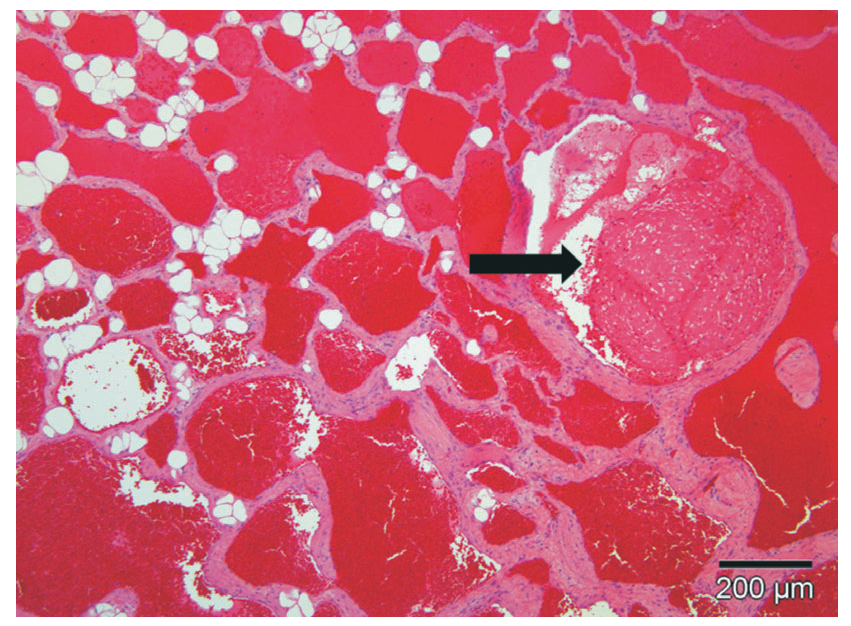

Fig. 3: Haematoxylin \& eosin-stained, routinely prepared histopathology sections showing small amounts of adipose tissue between vascular channels and a dilated vessel containing an organising fibrin thrombus (solid arrow). 

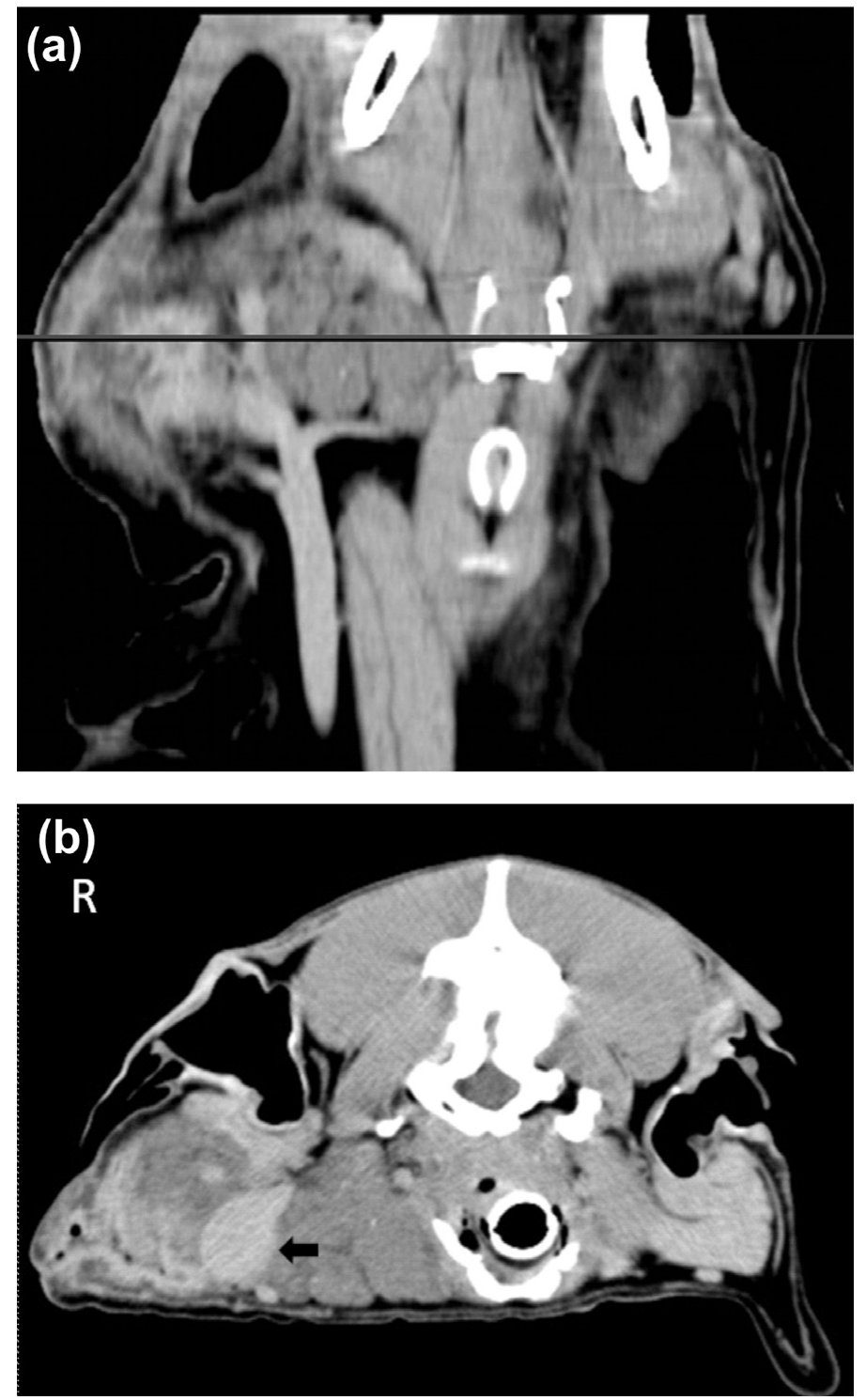

Fig. 4: Post contrast CT images of the cranial cervical caudal head region (window width $=$ 200 and window level $=40$ and slice thickness $1.5 \mathrm{~mm}$ ). a, Dorsal plane showing the right-sided mass just caudal to the angle of the mandible. $b$, Transverse plane through the caudal occipital area (represented by line in 4a). Note the right-sided mass effect when compared to the left side and the displaced trachea. Centrally the contrast enhanced hyperattenuating mandibular salivary gland can be seen (solid arrow) lying between the lateral and medial lobes of the mass. Note the peripheral contrast enhancement of the lateral mass indicative of remnant parotid tissue. On the extreme right side of the image are 2 hypoattenuating gas bubbles.

made 5 minutes after contrast injection showed no contrast enhancement of $90 \%$ of the mass with only a band of contrast uptake on the ventral, lateral and dorsal aspect of the affected lateral lobe (Fig. 4 $a, b)$. This appeared to be consistent with normal salivary tissue as the normal salivary glands uptake had a similar HU.

The owner declined further surgery. However, 14 months after diagnosis the dog is reported to be doing well although the mass has increased in size by approximately $30 \%$.

\section{DISCUSSION}

Lipomata are frequently seen in small animals; female dogs and entire male cats seem to be predisposed ${ }^{5}$. Tumours of adipose tissue can be divided into infiltrating lipomata, angiolipomata and liposarcomata ${ }^{6,7}$. Recently other benign tumours of adipose tissue, such as chondrolipoma, osteolipoma, fibrolipoma, and angiolipoleiomyoma have been

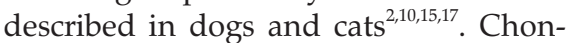
drolipomata and osteolipomata are thought to be related to metaplastic differentiation of a normal lipoma with the aetiology thought to be related to local trauma, normal mesenchymal reactivity and close association with periosteum and joints ${ }^{9,17}$. Angiolipomata are broadly classified as either infiltrative or solitary ${ }^{8,10}$ and appear to be rare tumours in dogs. To the authors' knowledge, only 2 cases of canine infiltrative angiolipomata have previously been described ${ }^{8,10}$. Histological examination of these tumours is necessary for a definitive diagnosis.

Infiltrative angiolipomata, like infiltrative lipomata, are locally aggressive as seen in the case reported here. The authors believe that the slow-growing nature of angiolipomata and the apparent lack of propensity to metastasise make debulking the masses a good treatment option. Solitary benign angiolipomata, on the other hand, respond well to surgical excision and have a low propensity for local recurrence $^{1,10}$

In this case, an infiltrative angiolipoma occurred in the parotid salivary gland and although large, the mass had much the same shape as the parotid salivary gland. Grossly the tumour was covered by a thin pseudocapsule.

On CT, the mass appeared to have broken through the pseudocapsule ventromedially to extend medially and form an additional neoplastic mass medial to the mandibular salivary gland. The HUs of the mass was slightly less than the normal soft tissues due to the lipomatous infiltration. Fat has a HU of about -80 to -100 and in infiltrating lipomata the tissue has a marked hypoattenuating appearance. In this case, the lack of marked hypoattenuation implies that other soft tissues were combined with the fat ${ }^{14}$ as can be seen in the histopathological sections. Computed tomography allowed good delineation of the tumour as reported previously in studies of infiltrative lipomata $^{14,20}$. Hyperattenuating areas visible on the periphery of infiltrating lipomata after the administration of contrast can occur post-surgery ${ }^{14}$. In this case, an incisional biopsy was taken 2 weeks prior to the CT examination and could have contributed to the ventrolateral rim hyperattenuation. However, the dorsal rim was far away from the surgical site and it is believed that the hyperattenuating rim was just remnant non-affected parotid tissue. The ventrolateral gas accumulation was due to the earlier surgical wound breakdown.

Minimal bleeding from the mass was noted when the tumour was incised. However, the haematoma that formed after biopsy may indicate that more persistent low-level bleeding may be a potential problem. The authors found it unusual that the mass was not enhanced after contrast administration. This could vary depending on the amount of blood vessels present in the mass ${ }^{21}$ or could be related to decreased vascular supply due to occlusion of the blood vessels by microthrombi.

Although neither this dog nor dogs reported in another study showed pain ${ }^{10}$, 
pressure on surrounding structures may cause pain, interference of movement, pressure atrophy and discomfort as seen with infiltrative lipomata ${ }^{12}$. Surgery can be used as the sole method of treatment, but other alternatives like external beam radiation could potentially be employed alone or in combination with surgery for local tumour control as is done with infiltrative lipomata ${ }^{13}$. In humans, hamartomatous angiolipoma and angiolipoma of the parotid salivary gland have been reported ${ }^{11,18}$ but no case report exists for their infiltration into the parotid salivary gland in dogs.

\section{CONCLUSION}

Although rare, it is important to consider angiolipomata as a differential diagnosis for subcutaneous nodules/masses. They can be difficult to diagnose with fine needle aspirates but biopsy gives the definitive diagnosis. This is particularly true when trying to differentiate sparsely vascularised lipomata from angiolipomata ${ }^{19}$. Although these tumours are very vascular they bleed less intraoperatively than expected but seem to constantly ooze from small capillaries. Computed tomography appeared to be superior to ultrasound in determining the extent and physical makeup of the mass

\section{AKNOWLEDGEMENTS}

The authors would like to thank Dr W. Wagner for performing the original ultrasound and CT examinations.

\section{REFERENCES}

1. Avci H, Aydogan A, Epiken E T, Tuna E, Toplu N 2008 Bir köpekte inguinal bölgede görülen anjiyolipom olgusu. Veteriner Bilimleri Dergisi 1: 93-95

2. Boisclair J, Dore M 2001 Uterine angiolipoleiomyoma in a dog. Veterinary Pathology 38: 726-728

3. Evans H E 1993 The digestive apparatus and abdomen. In Miller M E, Evans H E (eds) Miller's anatomy of the dog (3rd edn). Saunders, Philadelphia: 385-462

4. Fletcher C D M, Unni K K, Mertens F 2002 Pathology and genetics of tumours of soft tissue and bone. In Fletcher C D M, Unni K $\mathrm{K}$, Mertens F (eds) World health organization classification of tumours. IARC Press, Lyon: 19-46

5. Goldschmidt M H, Hendrick M J 2002 Tumors of the skin and soft tissues. In Meuten D J (ed.) Tumors of domestic animals. Iowa State Press, Iowa: 45-117

6. Hattori H 2005 Epidural angiolipoma is histologically distinct from its cutaneous counterpart in the calibre and density of its vascular component; a case report with review of the literature. Journal of Clinical Pathology 58: 882-883

7. Hendrick M J, Mahaffey E A, Moore F M, Vos J H 1998 Histiological classification of mesenchymal tumors of the skin and soft tissues of domestic animals. In Hendrick M J, Mahaffey E A, Moore F M, Vos J H (eds) World health organization international classification of tumors of domestic animals. Vol. 2. Armed Forces Institute of Pathology, Washington DC: 1-106

8. Jakab C, Németh T, Jerzsele Ã, Horváth Ã, Horváth L 2010 Kutya angiolipomájának diagnózisa klaudin-5 marker segítségével. Onkológiai eset ismertetése. Magyar Ãllatorvosok Lapja 132: 145-150

9. Katzer B 1989 Histopathology of rare chondroosteoblastic metaplasia in benign lipomas. Pathology Research and Practice 184: 437-445

10. Liggett A D, Frazier K S, Styer E L 2002 Angiolipomatous tumors in dogs and a cat. Veterinary Pathology 39: 286-289

11, Maiorano E, Capodiferro S, Fanelli B, Calabrese L, Napoli A, Favia G 2008
Hamartomatous angiolipoma of the parotid gland (sialoangiolipoma). Head and Neck Pathology 36-40

12. McChesney A E, Stephens L C, Lebel J, Snyder S, Ferguson H R 1980 Infiltrative lipoma in dogs. Veterinary Pathology 17: 316-322

13. McEntee M C, Page R L, Mauldin G N, Thrall D E 2000 Results of irradiation of infiltrative lipoma in 13 dogs. Veterinary Radiology and Ultrasound 41: 554-556

14. McEntee M C, Thrall D E 2001 Computed tomographic imaging of infiltrative lipoma in 22 dogs. Veterinary Radiology and Ultrasound 42: 221-225

15. Mutinelli F, Vascellari M, Melchiotti E, Bigolaro M, Bozzato E 2007 Intra-pelvic chondrolipoma in a dog. Journal of Comparative Pathology 137: 160-164

16. Nemanic S, London C A, Wisner E R 2006 Comparison of thoracic radiographs and single breath-hold helical CT for detection of pulmonary nodules in dogs with metastatic neoplasia. Journal of Veterinary Internal Medicine 20: 508-515

17. Ramirez G A, Altimira J, Garcia B, Vilafranca M 2010 Chondro-osteoblastic metaplasia in canine benign cutaneous lipomas. Journal of Comparative Pathology 142: 89-93

18. Reilly J S, Kelly D R, Royal S A 1988 Angiolipoma of the parotid: case report and review. Laryngoscope 98: 818-821

19. Swamy M, Chandrapuria V P, Kumar K 2004 Angiolipoma in a dog. Indian Journal of Veterinary Pathology 28: 141

20. Samii V F The thoracic wall. In Thrall D E 2007 (ed) Textbook of veterinary diagnostic radiology (5th edn). Saunders Elsevier, St Louis, MO: 512-524

21. Sibala J L, Chang C H J, Lin F, Thomas H T 1980 CT of angiolipoma of the breast. American Journal of Roentgenology 134: 840-841

22. Withrow S J, Vail D M 2007 Tumors of the skin and subcutaneous tuissue. In Withrow S J, Vail D M (eds) Withrow \& MacEwen's small animal clinical oncology (4th edn). Saunders Elsevier, St Louis, MO: 375-401 